\title{
Double-Side Electromagnetic Band Gap Structure for Improving Dual-Band MIMO Antenna Performance
}

\author{
Duong Thi Thanh $\mathrm{Tu}^{1}$, Nguyen Van $\mathrm{Hoc}^{1}$, Vu Van Yem ${ }^{2}$ \\ ${ }^{1}$ Posts and Telecommunications Institute of Technology, Vietnam \\ 2 School of Electronics and Telecommunications, Hanoi University of Science and Technology, Vietnam
}

Correspondence: Duong Thi Thanh Tu, tudtt@ptit.edu.vn

Communication: received 27 September 2016, revised 2 June 2017, accepted 6 June 2017

Online publication: 30 October 2017, Digital Object Identifier: 10.21553/rev-jec.135

The associate editor coordinating the review of this article and recommending it for publication was Dr. Nguyen Truong Khang.

\begin{abstract}
A double-side EBG (DS-EBG) structure with equivalent circuit model is proposed in this paper. Using double side structure with making $H$ shape on both surfaces, the novel EBG can get much compact cell size of $8.6 \times 8.6 \mathrm{~mm}^{2}$ which is equal to $11.8 \%$ the size of traditional EBG cell at the same of $2.6 \mathrm{GHz}$ resonant frequency. Besides, the proposed DS-EBG structure also gets dual stop band that is able to decrease mutual coupling for dual-band antenna. Using $1 \times 7$ DSEBG structures for dual-band MIMO system, several performance parameters of antenna are improved. Firstly, the mutual coupling between antenna elements gets $-40 \mathrm{~dB}$ in the lower band and $-30 \mathrm{~dB}$ in the higher one with narrow distance of 0.11 from feeding point to feeding point. Then, at $2.6 \mathrm{GHz}$, the antenna gain is increased significant by $160 \%$ as well as radiation efficiency of antenna is better. This improvement is unable to get in previous EBG studies.
\end{abstract}

Keywords- MIMO antenna, DGS, double-side EBG, mutual coupling.

\section{INTRODUCTION}

The Electromagnetic Band Gap (EBG) structures are periodic structures of dielectric materials and metallic conductor. Using these structures can decrease significantly the mutual coupling between antenna elements which is a huge challenge in MIMO system.

However, there are many methods have been proposed to solve the mutual coupling such as using transmission line decoupling technique [1], neutralization line technique [2], covering antenna patch by additional dielectric layers [3], using shorting pins for cancellation of capacitive polarization currents of substrate [4], or using photonic band gap structures [5-10]. Among these techniques, photonic band gap structures such as defected ground structure (DGS) and EBG get much attention recently because their periodic structures not only can suppress surface wave in certain frequency bands called "stop-band" and subsequently reduce mutual coupling between microstrip antennas but also improve other antenna characteristics such as gain, bandwidth or efficiency.

Various photonic band gap structures to subside the problem of mutual coupling have been proposed in previous researches. Most of these studies have focused on applications for single band antenna design. All of them have some benefits as well as drawbacks. The authors in [5] and [6] use simple rectangular DGS structures to reduce significantly mutual coupling but distance between antenna elements from feeding point to feeding point rather long. From [7] to [9], flexible shapes of EBG structure are designed. There is also coordination between DGS and EBG structures. However, total size of these EBG structures is quite large. In [10], a dual-layer EBG structure is proposed to get high isolation for MIMO systems but this structure is so complexity and difficult to fabricate. All above mentioned EBG structures are one-side EBG ones. They can decrease significantly the mutual coupling at different resonant frequencies and improve antenna gain but radiation efficiency has been reduced. Besides, they only apply for single band antenna. To improve isolation in dual-band MIMO system, the authors in [11] and [12] use a DGS structure and capacitive loaded loops, respectively. These structure are quite complexity but get insignificant isolation improvement. Further more, the $-10 \mathrm{~dB}$ bandwidth at low frequency band is narrow of $10 \mathrm{MHz}(1.25 \%)$.

Recently, wireless communication system has advanced incredibly, especially in mobile phone system. It is not only dimensions of end use equipment more and more decrease but also number of internal antennas in one terminal increase rapidly $[13,14]$. These demand the internal antennas must be both small in size to build in practical mobile handsets and have multiband for multi technologies. Therefore, seeking for solution to make multi-band gap for multi-band antenna in MIMO system as well as minimize structure is attractive topic which many studies focus.

In this paper, it is the first time a double-side EBG (DS-EBG) unit cell is created. Equivalent circuit model is given for novel EBG structure. Using the DS-EBG of $1 \times 7$ unit cell not only can suppress the surface waves for increasing the isolation between patch antennas of 


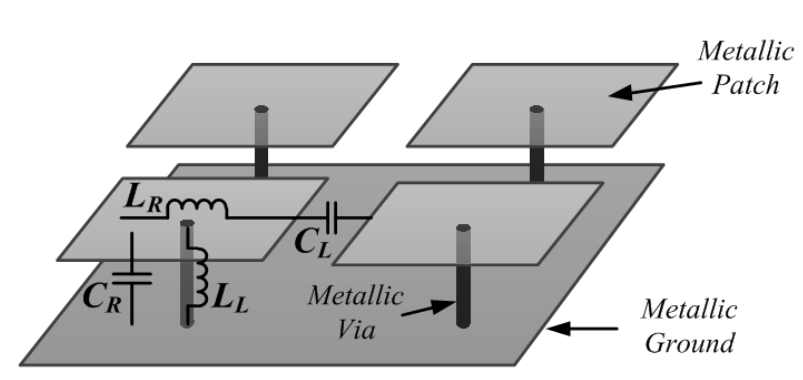

(a)

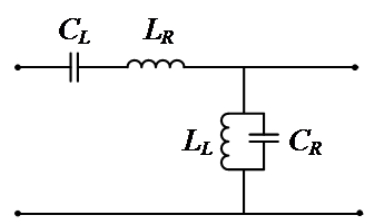

(b)

Figure 1. Traditional mushroom EBG structure: (a) Mushroom EBG model, (b) Equivalent circuit of unit cell.

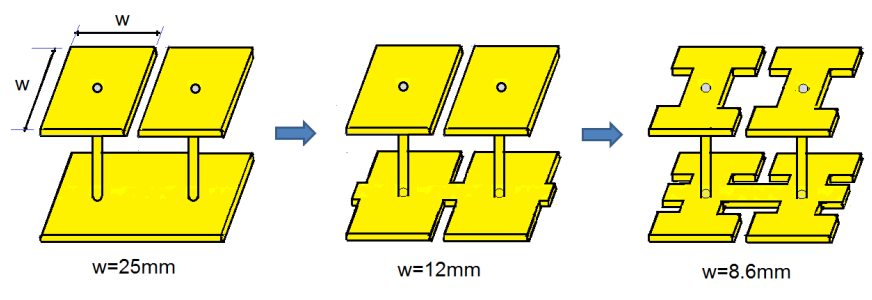

Figure 2. Design procedure of the proposed DS-EBG unit cell.

dual-band MIMO system but also improve antenna gain and efficient. This improvement can not get in previous EBG studies. Besides, making $\mathrm{H}$ shape and $\mathrm{H}$ shape with bridge of EBG structures on surface and on ground plane respectively reduced significantly the total size of DS-EBG structures compare to conventional EBG one while keeping the same resonant frequency.

The rest of this paper is organized as follow. In Section 2, the design of DS-EBG structure and its equivalent circuit are presented. Section 3 introduces dualband MIMO antenna which use DS-EBG structures to get high isolation while Section 4 and 5 are simulation and measurement results, respectively. Finally, some conclusions are provided in Section 6.

\section{DS-EBG Unit Cell and Modelling}

The EBG structure can suppress the surface waves thus reducing the mutual coupling between antennas in array if EBG structure parameters are designed properly. Center frequency of traditional EBG band gap is calculated approximately by [5]:

$$
f_{c}=\frac{1}{2} \pi \sqrt{L_{L} C_{L}}
$$

where $L_{L}$ and $C_{L}$ are as shown in Figure 1.

At $2.6 \mathrm{GHz}$ resonant frequency, size of conventional EBG cell, which is based on FR4 substrate with $1.6 \mathrm{~mm}$ height, is $25 \times 25 \mathrm{~mm}^{2}$. To reduce significantly total size

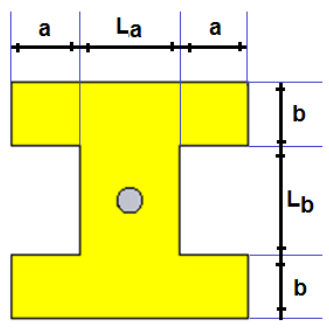

(a)

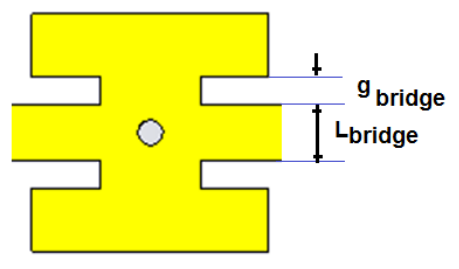

(b)

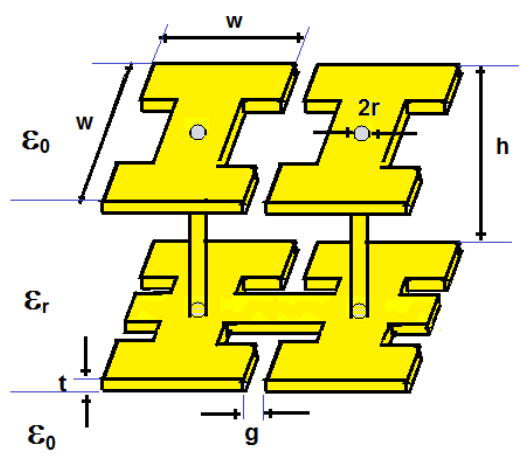

(c)

Figure 3. Unit cell of DS-EBG structure: (a) Top plane, (b) Bottom plane, (c) 3D.

Table I

The Geometry Dimensions of Proposed DS-EBG Structure Unit CELL

\begin{tabular}{|c|c|c|c|}
\hline Parameter & Dimension $\mathbf{( m m )}$ & Parameter & Dimension $\mathbf{( m m})$ \\
\hline $\mathrm{w}$ & 8.6 & $\mathrm{a}$ & 2.5 \\
\hline $\mathrm{h}$ & 1.6 & $\mathrm{~b}$ & 2.3 \\
\hline $\mathrm{t}$ & 0.035 & $g_{\text {bridge }}$ & 1 \\
\hline $\mathrm{g}$ & 1 & $L_{\text {bridge }}$ & 2 \\
\hline $\mathrm{r}$ & 0.5 & & \\
\hline
\end{tabular}

of EBG structures, a double-side EBG using $\mathrm{H}$ shape on surface and $\mathrm{H}$ shape with bridge on ground plane is proposed. Design procedure of DS-EBG unit cell is illustrated in Figure 2. It is clear that the DS-EBG cell gets the side of $12 \times 12 \mathrm{~mm}^{2}$ which has decreased by over $50 \%$. Using $\mathrm{H}$ shape on both sides, the proposed DS- EBG cell continues to reduce the size which is $8.6 \times$ $8.6 \mathrm{~mm}^{2}$. It is equal to $11.83 \%$ the size of traditional cell.

The detail dimensions of EBG unit cell are shown in Figure 3 and Table I where $\epsilon_{0}$ and $\epsilon_{r}$ are the permittivity of free space and the relative dielectric constant of the substrate, respectively.

The equivalent circuit of proposed DS-EBG structure unit cell is shown in Figure $4 . L_{\mathrm{c}-\mathrm{p}}$ and $L_{\mathrm{c}-\mathrm{g}}$ are equivalent inductances mainly cause by the circuit which is based by patch cell of the surface and ground cell of ground plane, respectively. The value of $L_{c-p}$ and $L_{c-g}$ are calculated using the following quasi-static equations [15]:

$$
L_{\mathrm{c}-\mathrm{p}}=L_{\mathrm{c}-\mathrm{g}}=\frac{\mu_{0} h}{2},
$$

where $\mu_{0}$ is permeability of free space.

$C_{\mathrm{g}}$ is the gap capacitance between meta patch [16] 


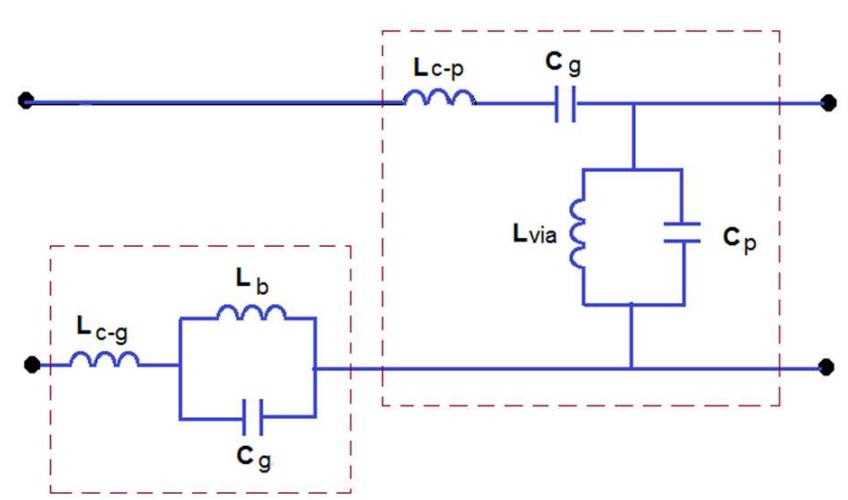

Figure 4. Equivalent circuit of the proposed DS-EBG unit cell.

and is calculated approximately as follows (3):

$$
C_{\mathrm{g}}=\frac{w \varepsilon_{0}\left(1+\varepsilon_{r}\right)}{\pi} \cosh ^{-1}\left(\frac{w+g}{g}\right) .
$$

$C_{p}$ is the capacitance between meta patch of surface and metal cell of ground plane. It is calculated approximately by Equation (4):

$$
C_{\mathrm{p}}=\frac{\varepsilon_{0} \varepsilon_{r}\left(w^{2}-a(w-2 b)\right)}{h} .
$$

$L_{\text {via }}$ is the inductance that is made of the via which is calculated using (5) as the following [15]:

$$
L_{\text {via }}=k_{1} h\left[\ln \left(\frac{2 h}{r}\right)+1\right]
$$

where $r$ is radius of the via in millimeters and $k_{1}=$ $0.2 \mathrm{nH} / \mathrm{mm}$.

$L_{\mathrm{b}}$ is the inductance of the microstrip lines between the metal cells of ground plane and depends on the physical implementation of the bridge. Thus, it given by:

$$
L_{\mathrm{b}}=k_{2}(g+2 a) \ln \left(2 \pi \frac{h}{L_{\text {bridge }}}\right) .
$$

From the Figure 4, it is obvious that the proposed DSEBG circuit consists two band-stop circuits. The first is mushroom-like EBG circuit whose resonant frequency is calculated by Equation (7):

$$
f_{1}=\frac{1}{2} \pi \sqrt{C_{\mathrm{g}} L_{\mathrm{via}}} .
$$

The second band-stop circuit is parallel $L_{\mathrm{b}} C_{\mathrm{g}}$ and $L_{\mathrm{c}-\mathrm{g}}$ combination whose resonant frequency is calculated by Equation (8):

$$
f_{2}=\frac{1}{2} \pi \sqrt{\left(L_{\mathrm{b}}+L_{\mathrm{c}-\mathrm{g}}\right) C_{\mathrm{g}}} .
$$

In addition, from the equivalent circuit we can see that the size of EBG cell is able to decrease thanks to raising the number of inductance and capacitance which is compared to traditional mushroom EBG structure.

Another way to calculate the resonant frequencies of general circuit of DS-EBG structure is using the resonant condition which the impedance of the circuit has its smallest magnitude and a phase angle of zero. From all above equations, we construct Matlab program to determine the $\mathrm{L}, \mathrm{C}$ values as well as optimize the EBG

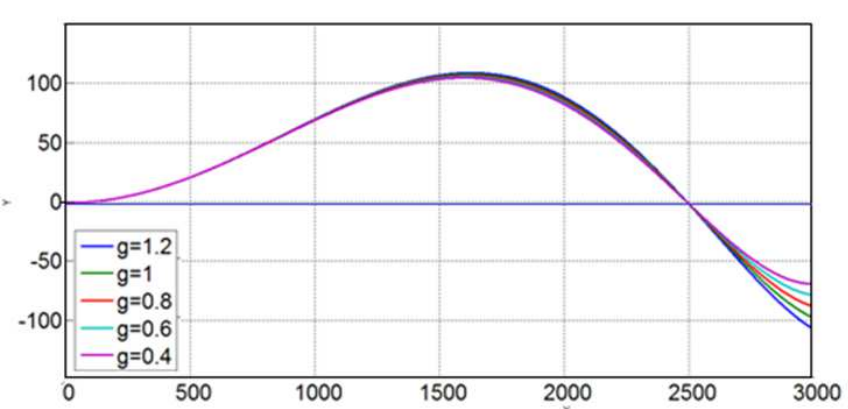

(a)

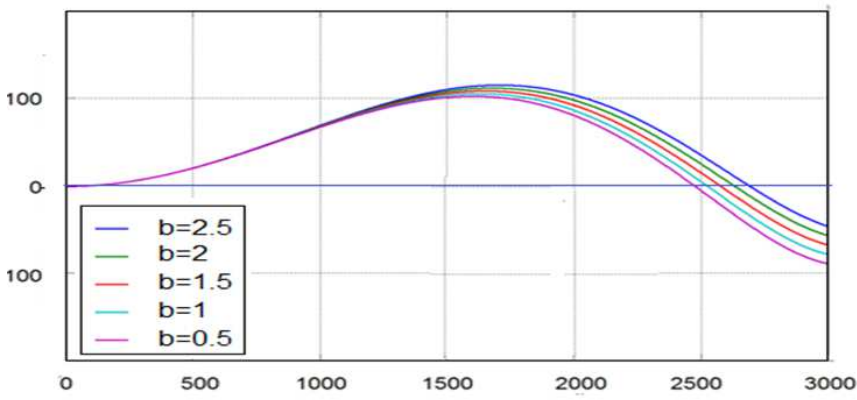

(b)

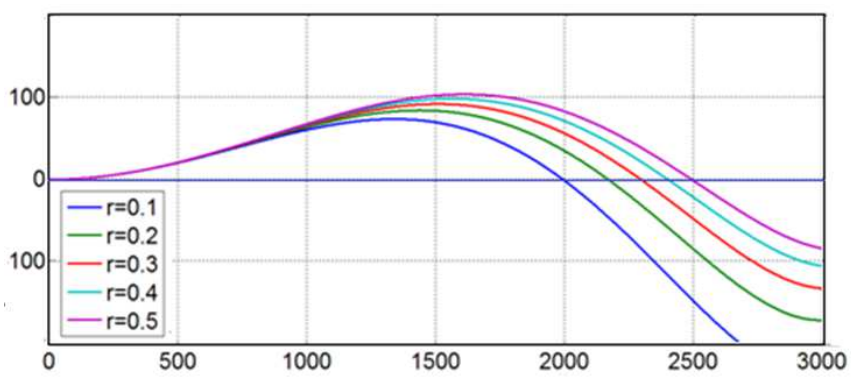

(c)

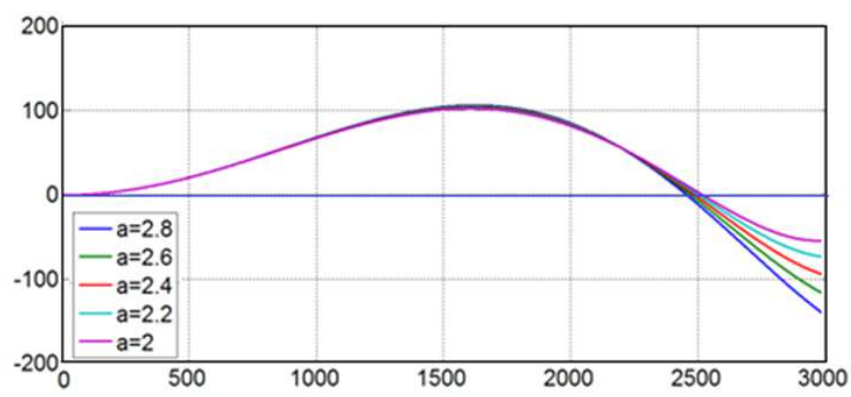

(d)

Figure 5. Calculated working frequency of EBG structure from changing dimension with cell size of $8.6 \mathrm{~mm}$ : (a) Changing $g$ dimension, (b) Changing $b$ dimension, (c) Changing $r$ dimension, (d) Changing a dimension.

dimensions to calculate and plot working frequency of EBG structure on the graph. These results are illustrated in Figure 5. It is obvious that the proposed DS-EBG operating around at $2.5 \mathrm{GHz}$ resonant frequencies and this resonant frequency is dependent mainly on $r$ and $b$ dimension parameters. 


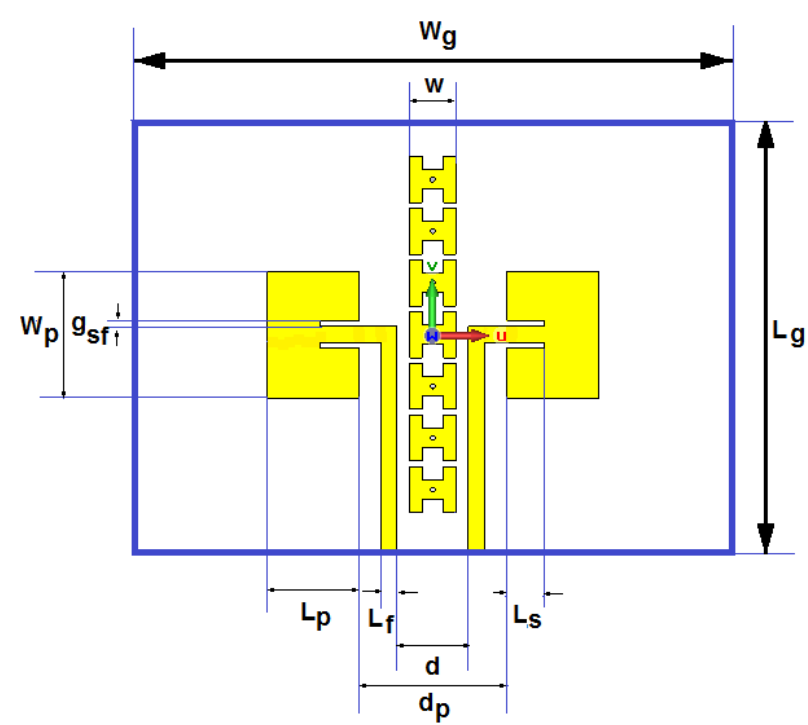

(a)

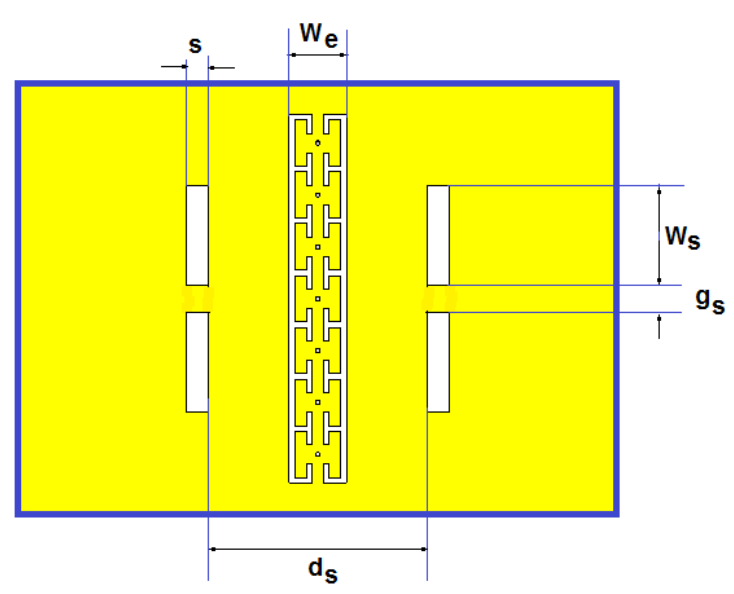

(b)

Figure 6. The dual-band MIMO antenna (a) top view (b) back view.

\section{Applying Double-Side EBG to Dual-Band MIMO ANTENNA}

To evaluate the effectiveness of proposed DS-EBG structure on MIMO antenna, $1 \times 7$ cells of DS-EBG structure is placed between two patch elements of MIMO antenna as illustrated in Figure 6. The antenna element as well as DS-EBG structures are made up of a rectangular radiating unit and a ground board which build on FR4 substrate of $1.6 \mathrm{~mm}$ thickness. To make dualband MIMO antenna, a double rectangular DGS is used. Using this DGS structure, the antenna also gets compact size and has high isolation of about $-20 \mathrm{~dB}$ in a wide band [17]. Detail dimensions of MIMO antenna structure as well as position of DS-EBG structure which is placed between radiation elements are presented in Table II.

The double-side EBG looks to be a hybrid structure of EBG and DGS hence it gets benefits of both structures. They are antenna gain and radiation efficiency improvement besides mutual coupling reduction.
Table II

The Geometry Dimensions of the Proposed MiMO Antenna Using Double-Side EBG STRuctures

\begin{tabular}{|c|c|c|c|}
\hline Parameter & Dimension $\mathbf{( m m )}$ & Parameter & Dimension (mm) \\
\hline$W_{p}$ & 23.5 & $g_{s f}$ & 1 \\
\hline$L_{p}$ & 17.1 & $\mathrm{~s}$ & 4 \\
\hline$W_{g}$ & 110 & $W_{s}$ & 18.45 \\
\hline$L_{g}$ & 80 & $g_{s}$ & 5.1 \\
\hline $\mathrm{d}$ & 13.2 & $d_{s}$ & 40.5 \\
\hline$d_{p}$ & 27.4 & $\mathrm{w}$ & 8.6 \\
\hline$L_{s}$ & 7.1 & $W_{e}$ & 10.6 \\
\hline$L_{f}$ & $3 . .1$ & & \\
\hline
\end{tabular}

\section{Simulation Results}

In this paper, the simulation of prototype antenna with CST software is presented. Two microstrip patch antennas using double rectangular DGS are designed at $2.6 \mathrm{GHZ}$ and $5.7 \mathrm{GHz}$. The size of each antenna is $23.5 \times 17.1 \mathrm{~mm}^{2}$ and the distance between them from center to center is $38.3 \mathrm{~mm}$ which equal $0.3 \lambda_{0}$ at lower band. From feeding point to feeding point, the distance is $13.2 \mathrm{~mm}$ which is equivalent $0.11 \lambda_{0}$ at $2.6 \mathrm{GHz}$ or $0.25 \lambda_{0}$ at $5.7 \mathrm{GHz}$ that is close distance comparison previous researches.

Figure 7(a) and Figure 7(b) illustrate how surface current distribute on antenna at 2.6 and $5.7 \mathrm{GHz}$ resonant frequency, respectively. From the Figure 7(a) it is clearly seen that at $2.6 \mathrm{GHz}$ resonant frequency, the serial DGS structures make the electric current on the antenna going from feeding line to $\mathrm{W}$ size of antenna patch into round the slots. Electric length of antenna, therefore, is increased. It means that the antenna size is reduced while resonant frequency is the same. Here, the patch size is $23.5 \times 17.1 \mathrm{~mm}^{2}$, which is nearly 42.5 $\%$ theoretical antenna size $\left(27 \times 35 \mathrm{~mm}^{2}\right)$ at the same resonant frequency of $2.6 \mathrm{GHz}$. From the Figure $7(\mathrm{~b})$, there is a different between $2.6 \mathrm{GHz}$ and $5.7 \mathrm{GHz}$ in surface current distribution on antenna. At $5.7 \mathrm{GHz}$, the serial DGS structures change the electric current going from feeding line to $\mathrm{W}$ size into perpendicular to $\mathrm{L}$ size of antenna patch. This, therefore, makes the second resonant frequency of antenna $(5.7 \mathrm{GHz})$. From surface current distribution, it is concluded that using serial rectangular DGS, the proposed antenna not only reduces the antenna patch size but also gets the dual band.

The $S$ parameters of the proposed antenna with and without novel double-side EBG structures are shown in Figure 8. From this plot, it is clearly seen that the antenna operates at two resonant frequencies: $2.6 \mathrm{GHz}$ for LTE application and $5.7 \mathrm{GHz}$ for WLAN. At low frequency, antenna reflection coefficient is $-40.13 \mathrm{~dB}$ and antenna bandwidth is $150 \mathrm{MHz}$. At high frequency, antenna reflection coefficient is nearly $-30 \mathrm{~dB}$ and antenna bandwidth is $250 \mathrm{MHz}$. All completely suit for LTE and WLAN application in portable equipments. Besides, compare to the MIMO antenna without DSEBG, the mutual coupling between antenna elements 


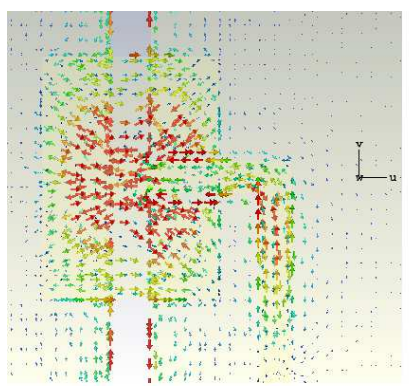

(a)

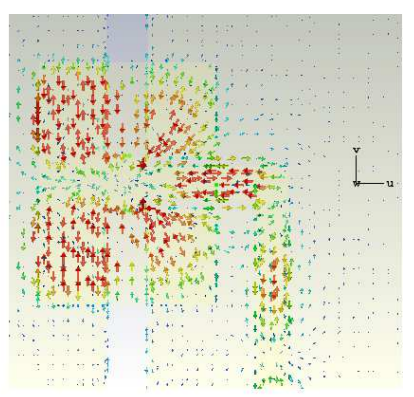

(b)
Figure 7. Surface current distribution on patch antenna (a) At $2.6 \mathrm{GHz}$ (b) At $5.7 \mathrm{GHz}$.

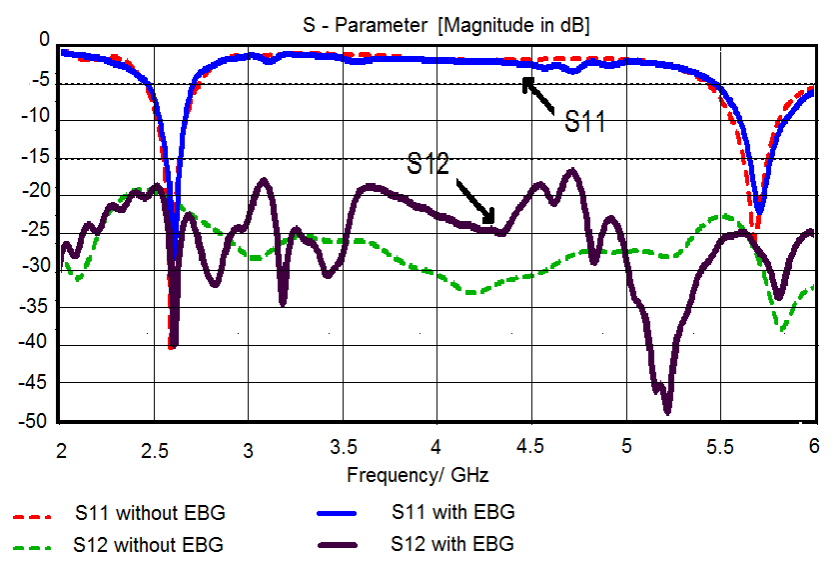

Figure 8. S parameters of the MIMO antenna with and without proposed DS-EBG structures.

of MIMO antenna with DS-EBG decreased sharply by $20 \mathrm{~dB}$ at $2.6 \mathrm{GHz}$ and reduce lightly by approximate $5 \mathrm{~dB}$ at $5.7 \mathrm{GHz}$.

The $3 \mathrm{D}$ and $2 \mathrm{D}$ radiation pattern of MIMO antenna without and with proposed double-side EBG structures are shown in Figure 10 and Figure 11 at $2.6 \mathrm{GHz}$ and $5.7 \mathrm{GHz}$ resonant frequencies, respectively. At $2.6 \mathrm{GHz}$ resonant frequency, the gain of antenna as well as radiation efficiency is improved significantly. The antenna gain gets $4.25 \mathrm{~dB}$ that is high gain at $2.6 \mathrm{GHz}$ and increases by $160 \%$ (from $2.63 \mathrm{~dB}$ to $4.25 \mathrm{~dB}$ ). Specially, the antenna radiation efficiency increases from $59 \%$ to $68.7 \%$. This improvement can not get in previous studies of one-side EBG structures (single layer as well as dual layer). The $2 \mathrm{D}$ radiation pattern of MIMO antenna with double-size EBG structures is still smooth like the MIMO antenna without DS-EBG with angular width $(3 \mathrm{~dB})$ is 83 degree. At $5.7 \mathrm{GHz}$ resonant frequency, the gain of antenna is improved lightly from $1.6 \mathrm{~dB}$ to $1.76 \mathrm{~dB}$ while the $2 \mathrm{D}$ radiation pattern is the same with angular width $(3 \mathrm{~dB})$ is 65.9 degree and the radiation efficiency is $39.8 \%$

In MIMO antenna system, correlation factor, which is so-called enveloped correlation coefficient (ECC), will be significantly degraded with higher coupling levels. The factor can be calculated from radiation patterns or scattering parameters. For a simple two-port network, assuming uniform multipath environment, the enveloped correlation $\rho_{e}$, simply square of the correlation coef-

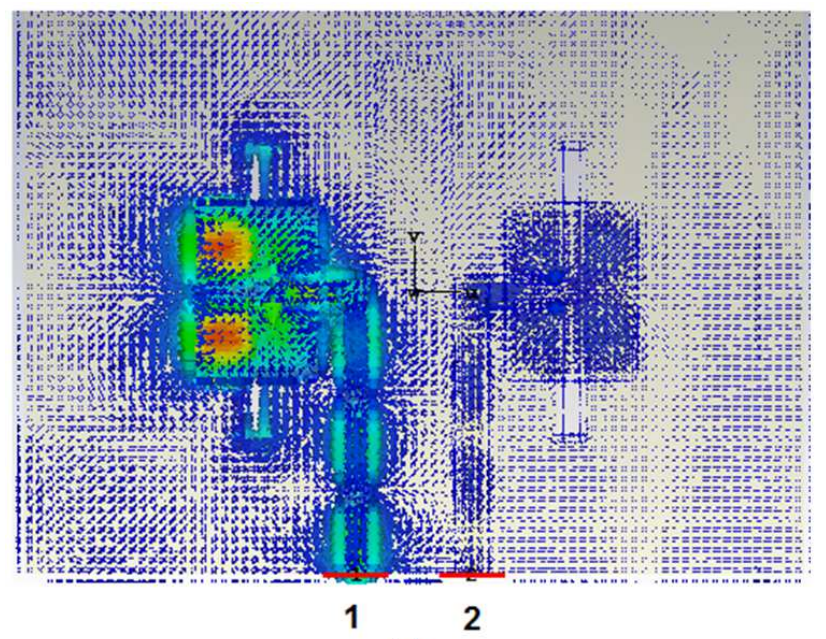

(a)

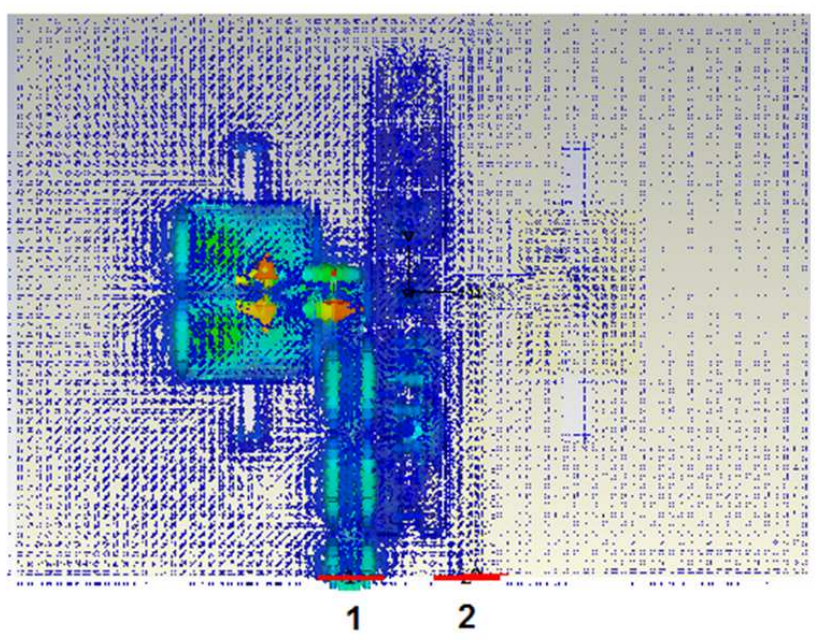

(b)

Figure 9. Surface current distribution on dual band MIMO antenna: (a) without DS-EBG, (b) with DS-EBG.

ficient $(\rho)$, can be calculated conveniently and quickly from S-parameters [18], as follows:

$$
\rho_{e}=\frac{\left|S_{11}^{*} S_{12}+S_{21}^{*} S_{22}\right|^{2}}{\left(1-\left|S_{11}\right|^{2}-\left|S_{21}\right|^{2}\right)\left(1-\left|S_{22}\right|^{2}-\left|S_{12}\right|^{2}\right)} .
$$

The correlation factor curves of proposed MIMO antenna at lower band and higher band are shown on Figure 12(a) and (b) respectively. From this figure, the MIMO antenna using double-side EBG structures has the simulated ECC lower than 0.15 at lower band and 0.07 at higher one. Therefore, it is quite suitable for mobile communication with a minimum acceptable correlation coefficient of 0.5 [19] as well as for LTE equipments with value of $|\rho| \preceq 0.3$ for the bands of interest [20].

Low radiation efficiency is one of drawbacks of patch antenna, especially using EBG structure. It is reason why this parameter has not presented in many previous EBG researches. Moreover, using convention EBG in antenna designs can enhance directivity and thus gain but efficiency usually get slightly degraded due to the energy coupled within the EBG. Our proposed DS-EBG 

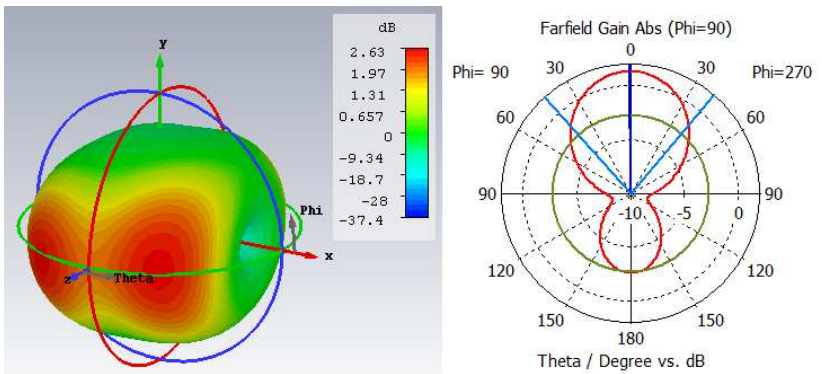

- farfield $(f=2.6)$

(a)
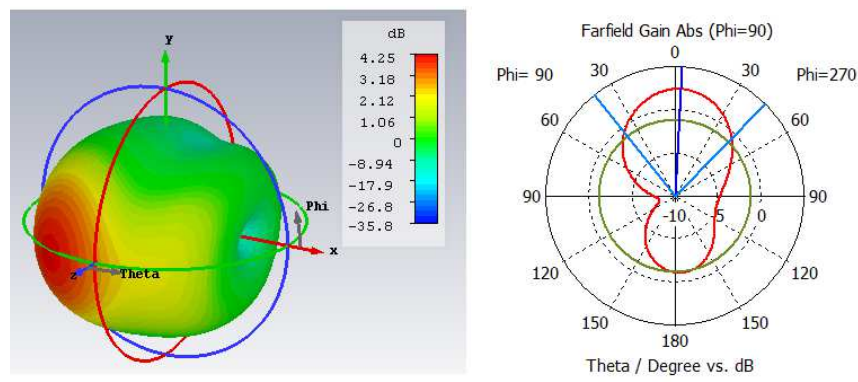

— farfield $(f=2.6)$

(b)

Figure 10. 3D and 2D antenna radiation pattern at $2.6 \mathrm{GHz}$ resonant frequency: (a) without DS-EBG, (b) with DS-EBG.
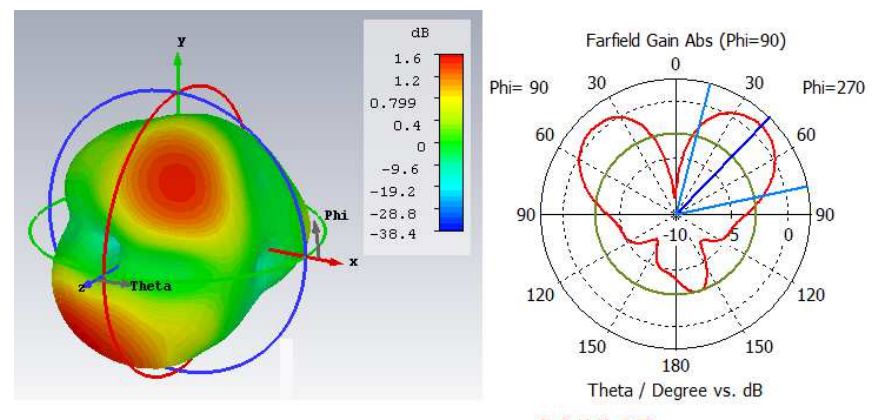

(a) — farfield $(f=5.7)$
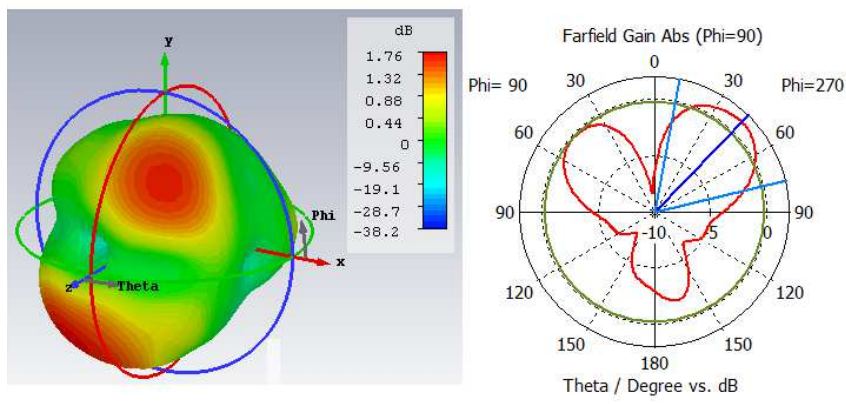

- farfield $(f=5.7)$

(b)

Figure $11.3 \mathrm{D}$ and $2 \mathrm{D}$ antenna radiation pattern at $5.7 \mathrm{GHz}$ resonant frequency: (a) without DS-EBG, (b) with DS-EBG.

presents the double-side structure that looks like hybrid EBG-DGS structure hence it gets benefits of both structures. They are antenna gain and radiation efficiency improvement besides mutual coupling reduction. Table III shows comparison between current structure and some previous EBG designs. While the total EBG structure size is the same and the mutual coupling

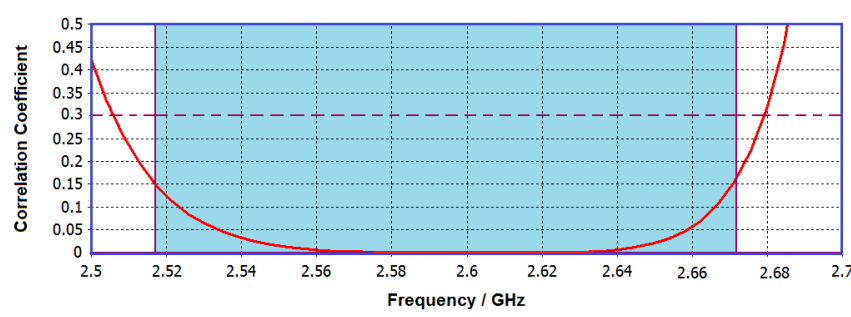

(a)

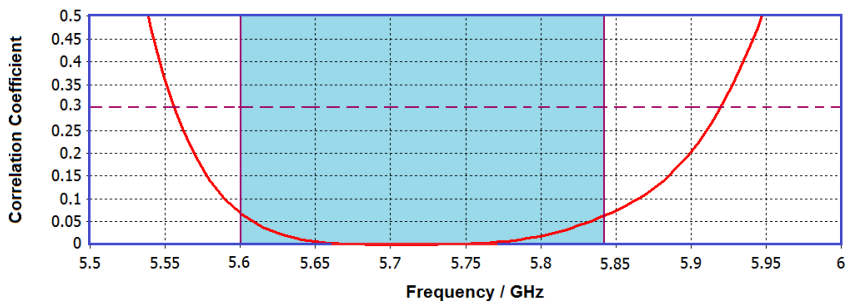

(b)

Figure 12. Correlation Factor $|\rho 12|$ curve for MIMO antenna (a) Lower band, (b) Higher band of operation.

Table III

Comparison Between Presented Design and Previous EBG RESEARCHES

\begin{tabular}{|l|c|c|c|l|l|l|}
\hline & (1) & (2) & (3) & (4) & (5) & \multicolumn{1}{|c|}{ (6) } \\
\hline Ref. [8] & 5.35 & $13.4 \times 36.5 \times 1.6$ & 0.6 & -43 & 6.86 & $\begin{array}{l}\text { Decreased } \\
\text { from 65\% } \\
\text { down to 53\% }\end{array}$ \\
\hline Ref. [9] & 2.4 & $29.1 \times 48.5 \times 1.6$ & 0.24 & -20 & $\begin{array}{l}\text { Not } \\
\text { given }\end{array}$ & Not given \\
\hline Ref. [10] & 2.5 & $10.4 \times 26 \times 3.2$ & 0.5 & -28 & 2.6 & $55.44 \%$ \\
\hline $\begin{array}{l}\text { Our } \\
\text { design }\end{array}$ & 2.6 & $10.6 \times 67.2 \times 1.6$ & 0.11 & -40 & 4.24 & $\begin{array}{l}\text { Increased } \\
\text { from 59\% to } \\
68.7 \%\end{array}$ \\
\hline
\end{tabular}

(1): Resonant Frequency $(\mathrm{GHz})$; (2): Total EBG structure size $\left(\mathrm{mm}^{3}\right)$

(3): Distance from feeding point to feeding point $\left(\lambda_{0}\right)$

(4): Mutual coupling between antenna elements $(\mathrm{dB})$

(5): Gain (dB); (6): Radiation Efficiency (\%)

Table IV

Comparison Between Presented Design and Other Dual-Band MIMO RESEARCHES

\begin{tabular}{|l|c|c|c|c|c|c|}
\hline & $\mathbf{( 1 )}$ & $\mathbf{( 2 )}$ & $\mathbf{( 3 )}$ & $\mathbf{( 4 )}$ & $\mathbf{( 5 )}$ & $\mathbf{( 6 )}$ \\
\hline Ref. [11] & 0.813 & 1.25 & 0.12 & -22 & -4 & $39.9 \div 41.6 \%$ \\
\hline Ref. [11] & 2.67 & 14.98 & 0.4 & -12 & 2.4 & $33.6 \div 67 \%$ \\
\hline Ref. [12] & 0.840 & 1.25 & 0.12 & -24 & -4 & $5 \%$ reduction,35\% \\
\hline Ref. [12] & 2.84 & 3.8 & 0.42 & -17 & 2.5 & $5 \%$ reduction, $67 \%$ \\
\hline $\begin{array}{l}\text { Our } \\
\text { design }\end{array}$ & 2.6 & 5.7 & 0.11 & -40 & 4.2 & $9.7 \%$ increase,68.7\% \\
\hline $\begin{array}{l}\text { Our } \\
\text { design }\end{array}$ & 5.7 & 4.3 & 0.35 & -30 & 1.76 & $39.8 \%$ \\
\hline
\end{tabular}

(1): Resonant Frequency (GHz); (2): -10 dB Bandwidth (\%)

(3): Distance from feeding point to feeding point $\left(\lambda_{0}\right)$

(4): Mutual coupling between antenna elements (dB)

(5): Max Gain (dB); (6): Radiation Efficiency (\%)

is low of $-40 \mathrm{~dB}$, the distance between two antenna elements from feeding point to feeding point has been about $18 \%-45 \%$ in comparison to similar previous researches. The high gain of $4.24 \mathrm{~dB}$ compare the other designs at the same resonant frequency. Specially, the antenna radiation efficiency has been improved that can not get in previous EBG studies.

Table IV shows comparison between dual-band MIMO antenna using double-side EBG structure and 


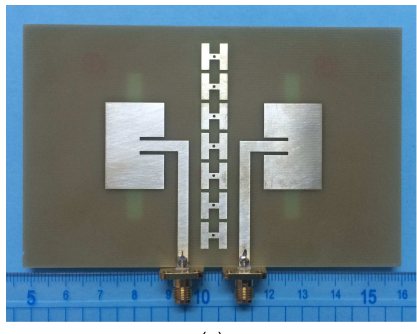

(a)

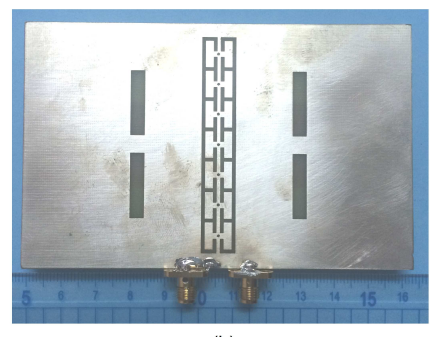

(b)
Figure 13. Fabricated double-side EBG applying for dual-band MIMO antenna: (a) Top view, (b) Bottom view.

some previous dual-band MIMO designs. The mutual coupling has been reduced about $70 \% \div 150 \%$ in comparison to similar distance from feeding point to feeding point of previous researches. Moreover, the antenna radiation efficiency has been improved that has solved the reduced efficiency character which is a challenge of MIMO antenna using mutual coupling reduction structures.

\section{Measurement Results}

The proposed double-side EBG which is applied for dual-band MIMO antenna is shown on Figure 3. Both MIMO antenna and $1 \times 7$ EBG structure unit cell are fabricated on FR4 substrate with height of $1.6 \mathrm{~mm}$.

The measure result of $S$ parameters is compared with simulation result in Figure 14. It is clearly seen that the MIMO antennas operate at $2.6 \mathrm{GHz}$ and $5.7 \mathrm{GHz}$ with $150 \mathrm{MHz}$ and $250 \mathrm{MHz}$ bandwidth, respectively. At the $2.6 \mathrm{GHz}$ resonant frequency, the antenna reflection coefficient is $-15 \mathrm{~dB}$ and the mutual coupling is $-30 \mathrm{~dB}$. At the $5.7 \mathrm{GHz}$ resonant frequency, the antenna reflection coefficient gets much better of $-38 \mathrm{~dB}$ and the mutual coupling gets $-37 \mathrm{~dB}$. From this measurement, it can be concluded that the measured results agree well with the simulated ones. Moreover, using double-size EBG structures can reduce significantly the mutual coupling between antenna elements in dual band MIMO system.

\section{Conclusion}

In this paper, a double-side EBG structure applying to dual-band MIMO antenna is proposed. The DS-EBG structure which uses $\mathrm{H}$ shape on the patch plane and $\mathrm{H}$ shape with bridge on the ground one makes the size of DS-EBG cell much more compact. Using this structure, the dual band MIMO antenna not only reduces the mutual coupling between antenna elements of $20 \mathrm{~dB}$ but also improve the antenna gain. Especially at $2.6 \mathrm{GHz}$, the antenna gain gets $4.25 \mathrm{~dB}$. This value is rather high to compare with other antennas operating at the same resonant frequency. Furthermore, the antenna radiation efficiency at this band has been improved that can not get in previous EBG studies. The proposed dual-band MIMO antenna at $2.6 \mathrm{GHz}$ and $5.7 \mathrm{GHz}$ is suitable for LTE and WLAN applications in the portable terminals.

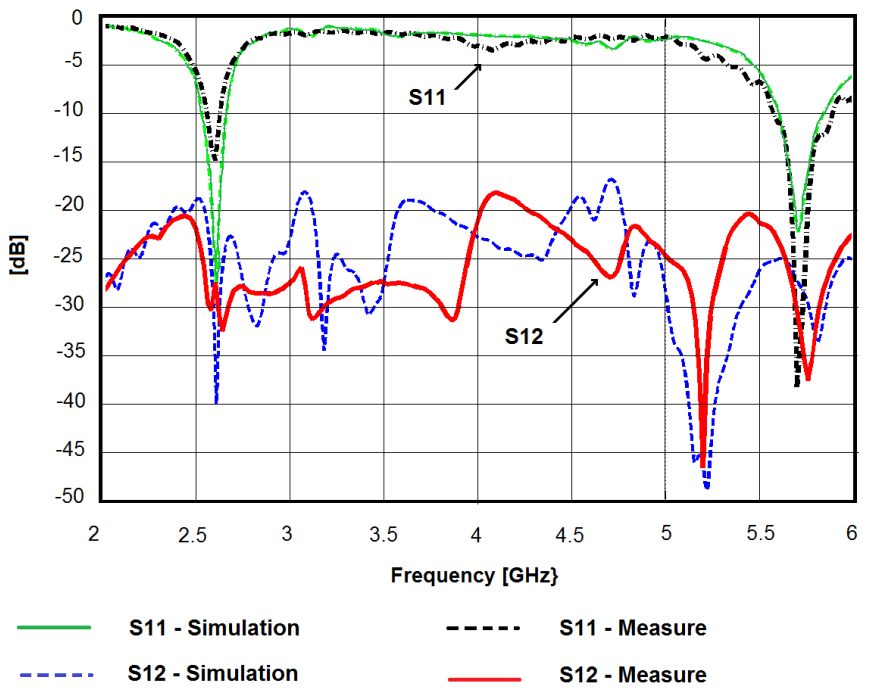

Figure 14. Measured values of S parameters of MIMO antenna using double-side EBG structures.

\section{REFERENCES}

[1] S.-C. Chen, Y.-S. Wang, and S.-J. Chung, “A decoupling technique for increasing the port isolation between two strongly coupled antennas," IEEE Transactions on Antennas and Propagation, vol. 56, no. 12, pp. 3650-3658, 2008.

[2] S.-W. Su, C.-T. Lee, and F.-S. Chang, "Printed mimoantenna system using neutralization-line technique for wireless usb-dongle applications," IEEE Transactions on Antennas and Propagation, vol. 60, no. 2, pp. 456-463, 2012.

[3] N. Alexopoulos and D. Jackson, "Fundamental superstrate (cover) effects on printed circuit antennas," IEEE Transactions on Antennas and Propagation, vol. 32, no. 8, pp. 807-816, 1984.

[4] M. M. Nikolic, A. R. Djordjevic, and A. Nehorai, “Microstrip antennas with suppressed radiation in horizontal directions and reduced coupling," IEEE Transactions on Antennas and Propagation, vol. 53, no. 11, pp. 3469-3476, 2005.

[5] N. K. Kiem, H. N. B. Phuong, Q. N. Hieu, and D. N. Chien, "A novel metamaterial mimo antenna with high isolation for wlan applications," International Journal of Antennas and Propagation, vol. 2015, Article ID 851904, 9 page, 2015.

[6] M. A. Abdalla and A. A. Ibrahim, "Compact and closely spaced metamaterial mimo antenna with high isolation for wireless applications," IEEE Antennas and Wireless Propagation Letters, vol. 12, pp. 1452-1455, 2013.

[7] S. Dhamanka and S. Lopes, "Mutual coupling reduction techniques in microstrip patch antennas: survey," International Research Journal of Engineering and Technology, vol. 3, no. 3, pp. 1064-1069, 2016.

[8] M. Naser-Moghadasi, R. Ahmadian, Z. Mansouri, F. B. Zarrabi, and M. Rahimi, "Compact ebg structures for reduction of mutual coupling in patch antenna mimo arrays," Progress In Electromagnetics Research C, vol. 53, pp. 145-154, 2014.

[9] Z. Abidin, Y. Ma, R. A. Abd-Alhameed, K. N. Ramli, D. Zhou, M. Bin-Melha, J. M. Noras, and R. Halliwell, "Design of 2x2 u-shape mimo slot antennas with ebg material for mobile handset applications." Progress In Electromagnetics Research (PIER), vol. 7, no. 1, pp. 81-85, 2011.

[10] S. Ghosh, T.-N. Tran, and T. Le-Ngoc, "Dual-layer ebgbased miniaturized multi-element antenna for mimo systems," IEEE Transactions on Antennas and Propagation, vol. 62, no. 8, pp. 3985-3997, 2014. 
[11] M. S. Sharawi, A. B. Numan, M. U. Khan, and D. N. Aloi, "A dual-element dual-band mimo antenna system with enhanced isolation for mobile terminals," IEEE antennas and wireless propagation letters, vol. 11, pp. 1006-1009, 2012.

[12] M. S. Sharawi, A. B. Numan, and D. N. Aloi, "Isolation improvement in a dual-band dual-element mimo antenna system using capacitively loaded loops," Progress In Electromagnetics Research, vol. 134, pp. 247-266, 2013.

[13] H. Wong, K.-M. Luk, C. H. Chan, Q. Xue, K. K. So, and H. W. Lai, "Small antennas in wireless communications," Proceedings of the IEEE, vol. 100, no. 7, pp. 2109-2121, 2012.

[14] C. Rowell and E. Y. Lam, "Mobile-phone antenna design," IEEE Antennas and Propagation Magazine, vol. 54, no. 4, pp. 14-34, 2012.

[15] K. H. Kim and J. E. Schutt-Ainé, "Analysis and modeling of hybrid planar-type electromagnetic-bandgap structures and feasibility study on power distribution network applications," IEEE Transactions on Microwave Theory and Techniques, vol. 56, no. 1, pp. 178-186, 2008.

[16] F. Yang and Y. Rahmat-Samii, Electromagnetic band gap structures in antenna engineering. The Cambridge RF and Microwave Engineering Series, Cambridge university press Cambridge, UK, 2009.

[17] D. T. T. Tu, N. Van Hoc, H. Quan, and V. Van Yem, "Compact mimo antenna with low mutual coupling using defected ground structure," in Proceedings of the IEEE Sixth International Conference on Communications and Electronics (ICCE 2016). IEEE, 2016, pp. 242-247.

[18] J. Thaysen and K. B. Jakobsen, "Envelope correlation in $(\mathrm{n}, \mathrm{n})$ mimo antenna array from scattering parameters," Microwave and optical technology letters, vol. 48, no. 5, pp. 832-834, 2006.

[19] M. P. Karaboikis, V. C. Papamichael, G. F. Tsachtsiris, C. F. Soras, and V. T. Makios, "Integrating compact printed antennas onto small diversity/mimo terminals," IEEE Transactions on Antennas and Propagation, vol. 56, no. 7, pp. 2067-2078, 2008.

[20] 3GPP TS 36.101, V8.3.0, "Eutra user equipment radio transmission and reception," Tech. Rep., Sept. 2008.

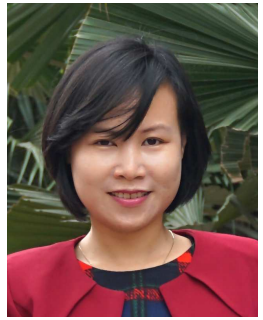

Duong Thi Thanh Tu received B.E, M.E degrees in Electronics and Telecommunications from Hanoi University of Science and Technology and National University in 1999 and 2005 , respectively. She now is a lecturer at Faculty of Telecommunications 1 , Posts and Telecommunications Institute of Technology. She, presently is doing $\mathrm{PhD}$ at $\mathrm{School}$ of Electronics and Telecommunications, Hanoi University of Science and Technology. Her current research centers on antenna design for next generation wireless networks as well as the special structure of material such as metamaterial, electromagnetic band gap structure.

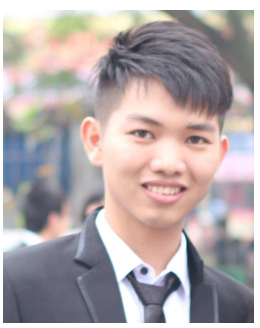

Nguyen Van Hoc received B.E. degree in Electronics and Telecommunications from Posts and Telecommunications Institute of Techno$\operatorname{logy}$ in March 2016. He now works as a radio optimization engineer for Technical center zone 1 - Viettel Network.

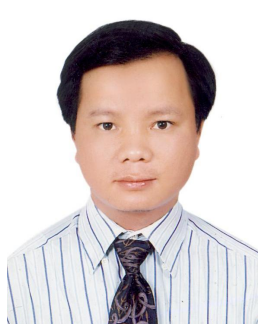

Vu Van Yem was born in 1975 in Hai Phong, Vietnam. He received the Ph.D. degree in communications from Department of Electronics and Communications, TELECOM ParisTech (formerly ENST Paris) France in 2005. From 2006 to 2007 , he was a postdoctoral researcher at the Department of Hyper-frequencies and Semiconductor, Institute of Electronics, Microelectronics and Nanotechnology (IEMN) France. He has been qualified to be named as Associate Professor since November, 2009. Currently, he is the Deputy - Dean of Graduate School and the Head of the Department of Telecommunication Systems, School of Electronics and Telecommunications, Hanoi University of Science and Technology, Vietnam. His area of expertise are microwave engineering, antenna, chaos-based digital communications as well as wireless communication and localization systems. 